\title{
Advances on the Behavior Characterization of FRP-Anchored Carbon Fiber-Reinforced Polymer (CFRP) Sheets Used to Strengthen Concrete Elements
}

\author{
Sergio F. Breña*, and Geoffrey N. McGuirk
}

(Received January 9, 2013, Accepted February 11, 2013)

\begin{abstract}
Strengthening concrete structures using FRP composites is a commonly considered technology in many practical situations. The success of the strengthening intervention largely depends on adequate bond between FRP sheets and the concrete substrate. In recent years, techniques to anchor FRP sheets in applications where sheets must develop strength in a short length have been proposed. One of these techniques includes use of FRP anchors embedded into the concrete substrate and forming part of the composite strengthening system. This paper presents the results of studies conducted recently at the University of Massachusetts Amherst to advance the understanding on the behavior of FRP anchored systems.
\end{abstract}

Keywords: FRP sheets, FRP anchors, FRP bond, concrete strengthening.

\section{Introduction}

The increase in the demand for use of fiber-reinforced polymer (FRP) composite sheets to strengthen existing structures has resulted in a wealth of research to provide engineers with tools to make their designs more efficient. It is well known that in order to better utilize the FRP material high strength, debonding from the concrete surface must be eliminated or delayed. Because of this limiting design condition, the bond performance between FRP sheets and the surface of concrete has been studied extensively by researchers in the past (Bizindavyi and Neale 1999; Chajes et al. 1996; Smith and Teng 2002a; Pellegrino et al. 2008; Yao et al. 2005), among others. These studies have resulted in the development of models that can accurately calculate the bond strength of the system for use in design. Some of these models are based on statistical reduction of available tests (Smith and Teng 2002), and other models are based on fracture mechanics theory (Coronado and Lopez 2008).

Anchoring FRP sheets to delay or prevent debonding has been proposed to develop higher stresses in the FRP sheets and make the use of the FRP materials more efficient. Various ways of anchoring the FRP sheets to concrete have been investigated, including the use of transverse sheets or straps (Coronado and Lopez 2008; Breña et al. 2003; Kotynia et al. 2008), using mechanical anchors (Elsayed et al. 2009), wrapping the end of sheets in rods embedded in grooves formed into the

University of Massachusetts-Amherst, Amherst, MA, USA.

*Corresponding Author; E-mail: brena@ecs.umass.edu Copyright ( $\odot$ The Author(s) 2013. This article is published with open access at Springerlink.com concrete (Eshwar et al. 2008; Khalifa et al. 1999), or forming and anchoring the FRP sheets using FRP anchors (Eshwar et al. 2008; Orton et al. 2008; Ozbakkaloglu and Saatcioglu 2009).

More recently the technique involving anchorage of FRP sheets using field formed FRP anchors has been identified as a means to anchor FRP sheets to concrete elements (Niemitz et al. 2010; Kim and Smith 2009). The number of studies in this area is still limited. The goal of the research presented in this paper is to expand the knowledge on the behavior of FRP sheets anchored using FRP anchors to allow development of design recommendations in the future.

\section{Issues Relating to Bond of FRP Sheets on Concrete Surfaces}

FRP sheets bonded to concrete elements often fail prematurely by debonding. For this reason the bond behavior of FRP sheets on concrete surfaces has been studied by many researchers. To improve the understanding of interfacial bond stresses various researchers have investigated the stress distribution of FRP strengthening systems bonded to concrete (Pellegrino et al. 2008; Mazzotti et al. 2009; Nakaba et al. 2001). Stress distributions have been determined using experimental investigations or analytical (finite element) modeling. One of the limitations of these studies is that researchers have primarily focused on studying stresses developed along the centerline of FRP sheets. The most commonly used elements for these studies are either beams containing FRP sheets bonded to the tensile face or concrete blocks in which the sheets are subjected to a tensile force to generate direct shear stresses at the bond line. In all the studies contained in the literature the primary focus has been on strains and stresses that develop along the center of the 
sheets or plates, thereby limiting an understanding of the stress field that generates across the width of the sheets. A non-uniform stress distribution is generated across the width FRP sheets bonded to concrete with higher stresses near the middle of the sheet that decrease toward the sheet edges. This phenomenon, which has important implications in the performance of bonded sheets, has not been studied in detail in the literature except for studies reported by Subramaniam et al. (2007).

\subsection{Analytical Modeling of FRP Sheets Bonded to Concrete}

For design, bond models that concentrate on providing accurate estimates of bond strength are acceptable. From a behavioral perspective, however, models that allow estimation of the force-displacement relationship between FRP sheets and concrete substrates are better suited (Lu et al. 2005; Nakaba et al. 2001). The performance of two of these models is compared here for use in finite element simulations of FRP sheets bonded to concrete presented later in this paper. A summary of the key equations defining the models is given here, while complete details are given in the original references.

\subsubsection{Bond-Slip Model Proposed by Lu et al. (2005)}

Lu et al. (2005) conducted a critical review of available bond strength models and shear stress-slip relationships. They compared the performance of the different models using an extensive experimental database of single and double shear tests, and suggested a series of models based on empirical calibration of results from finite element simulations. The simplified version of their basic model, which requires fewer parameters to define it is given by:

$$
\begin{aligned}
& \tau=\tau_{\max } \sqrt{\frac{s}{s_{o}}} \text { if } s \leq s_{o} \\
& \tau=\tau_{\max } e^{-\alpha\left(\frac{s}{s_{o}}-1\right)} \quad \text { if } s>s_{o}
\end{aligned}
$$

where the slip, $s_{o}$, is the slip at peak stress, $\tau_{\max }$, and both quantities depend on the sheet width factor $\beta_{w}$ and the concrete tensile strength $f_{t}$ :

$$
\begin{gathered}
s_{o}=0.0195 \beta_{w} f_{t} \\
\tau_{\text {max }}=1.5 \beta_{w} f_{t}
\end{gathered}
$$

and the sheet width factor $\beta_{w}$ is given by:

$$
\beta_{w}=\sqrt{\frac{2.25-b_{f} / b_{c}}{1.25+b_{f} / b_{c}}}
$$

In these equations $\tau_{\max }$, and $f_{t}$ are in MPa and $s_{o}$ is in mm. The widths $b_{f}$ and $b_{c}$ are the FRP sheet and concrete widths, respectively.

\subsubsection{Bond-Slip Model Proposed by Nakaba et al.} (2001)

Nakaba et al.'s model is based on the form that Popovics (1973) proposed to model the behavior of concrete in compression. The bond stress-slip relationship is calculated using Eq. (2):

$$
\frac{\tau_{b}}{\tau_{b, \max }}=\frac{s}{s_{\max }} \times \frac{n}{(n-1)+\left(S / S_{\max }\right)^{n}}
$$

where $\tau_{b}$ is the local bond stress, $\tau_{b, \text { max }}$ is the maximum bond stress, $s$ is the slip, $s_{\max }$ is the slip at peak bond stress, and $n$ is a constant that defines the shape of the bond-slip curve taken approximately equal to 3 .

The model by Nakaba et al. (2001) is independent of the width of FRP relative to the concrete width in contrast with the model proposed by $\mathrm{Lu}$ et al. (2005). The FRP sheet width factor $\beta_{w}$ was derived from tests where sheets were bonded to concrete prisms, where an influence of sheet width on bond strength was experimentally determined. The width factor can be easily determined in flexural strengthening cases or in bond tests using concrete prisms. However this factor is not as easily determined in shear strengthening applications or strengthening of structural walls.

\subsection{Stress Transfer Zone}

Stress distribution studies have resulted in proposals for development of design equations of FRP plates bonded to concrete surfaces. The results of stress distribution studies conducted in reinforced concrete elements containing surface bonded plates (steel or FRP) in the past have led to the definition of a stress transfer zone (Bizindavyi and Neale 1999; Subramaniam et al. 2007). The stress transfer zone is defined as the length over which peak strains and stresses are developed in an FRP sheet as increased loading is applied. The stress transfer zone is also related to the effective length of FRP sheets $\left(L_{e}\right)$, a parameter needed in some design models for surface bonded FRP sheets (Yao et al. 2005). Debonding of FRP sheets typically initiates after maximum stresses are reached at the end of the stress transfer zone at peak force applied to the FRP sheet. The debonding front propagates along the bonded sheet at approximately constant force without a change in the effective length until the debonding front reaches the end of the sheet. The stress transfer zone translates toward the unloaded end of the FRP sheet without a significant increase in force.

Increasing the bonded length of an adhesively bonded FRP sheet beyond the effective length does not increase the bond strength since propagation of debonding occurs at same load once the stress transfer zone is fully established (Subramaniam et al. 2007). However, the debonding process occurs gradually as the debonding front propagates toward the unloaded end of the sheet, so an increase in bonded length beyond $L_{e}$ results in ductility enhancement of the bonded FRP system.

\subsection{Anchored FRP Sheets to Concrete}

The stresses that can be developed in FRP sheets bonded to concrete represent only a fraction of the rupture strength of the sheet. In order to make FRP strengthening applications more efficient, investigators have researched ways to 
anchor the sheets so that failure by debonding is precluded. Various ways of anchoring the FRP sheets to concrete have been investigated, including the use of transverse sheets or straps (Breña et al. 2003; Kotynia et al. 2008); using mechanical anchors (Elsayed et al. 2009), wrapping the end of sheets in rods embedded in grooves formed into the concrete (Eshwar et al. 2008; Khalifa et al. 1999); or forming and anchoring the FRP sheets using FRP anchors (Eshwar et al. 2008; Orton et al. 2008; Ozbakkaloglu and Saatcioglu 2009). Many of these anchoring methods have shown promising results but no detailed information has been published to date that would allow development of design procedures for anchored FRP sheets.

In contrast with the number of studies that have focused on studying the bond behavior of sheets to concrete, similar studies of anchored FRP sheets are largely lacking. Analytical modeling of anchored FRP sheets has not been studied in any significant detail to date because very little information exists on the behavior of FRP anchors. The models that have been used to study the bond behavior of FRP sheets (often 2D models) are not applicable to cases in which anchors are used because a complex strain distribution exists in the plane of the FRP sheet near anchor locations. Two-dimensional (plane stress) models, although widely used to understand the bond behavior of FRP sheet-concrete systems, can only capture the stress distribution along the centerline of the FRP sheet. These modeling shortcomings impair the use of these promising anchoring techniques to practice. A method to model anchor behavior using experimentally calibrated finite element models is given in this paper. It is recognized that refinements of the proposed models, in particular the force-displacement relationships used to model anchor behavior, may be required as new experimental data become available.

\section{Experimental Investigations of Anchored FRP Sheets}

A series of laboratory experiments have been conducted in the structural engineering laboratory at the University of Massachusetts-Amherst over the last few years to improve an understanding in the behavior of FRP sheets anchored using FRP anchors (Niemitz et al. 2010; McGuirk and Breña 2012). The tests were designed as a first step to identify the parameters that affect the behavior of FRP sheets with supplementary FRP anchors. These tests also allowed an identification of parameters that likely contributed to differences in performance such as size of anchor (anchor diameter, anchor depth, anchor splay diameter), number of anchors, lateral and longitudinal placement of anchor, and number of FRP layers. A key aspect of these tests was to identify the potential failure modes of the FRP anchored system and techniques to avoid failure modes that resulted in undesirable performance. Adequate performance was judged on the basis of the ability of the system to develop higher force than equivalent bonded-only FRP sheets. The higher performing anchoring arrangements were those that developed a higher fraction of the rupture strength of the FRP sheets. For adequate performance, premature FRP anchor failures were to be avoided prior to rupture of the FRP sheet.

The tests were designed as direct-shear specimens to generate interfacial shear stresses between the surface of concrete and the FRP sheets. Reinforced concrete blocks were used as the concrete substrate for the FRP sheets. The concrete blocks were post-tensioned to a self-reacting frame to avoid slip of the block during loading of the FRP sheet. Each block was used for a minimum of two and a maximum of four direct-shear tests depending on the sides available to conduct testing. Concrete surfaces were prepared by grinding and subsequently removing loose concrete particles using pressurized air and vacuuming. A schematic illustrating the general geometry of the test setup is shown in Fig. 1.

The FRP sheets had a region overhanging the concrete block to allow application of the load. Load was applied to the entire FRP sheet width through steel plates bonded at the edge of the sheets during the FRP sheet fabrication process. The edge of the FRP sheets was sufficiently far from the test region to eliminate the influence from local stress concentrations associated to uneven distribution of the applied load. Additionally, the initial region on the loading end of FRP sheet lying over the concrete block was left un-bonded to prevent corner spalling of the concrete blocks and to avoid a sudden load reduction on the FRP sheet during testing.

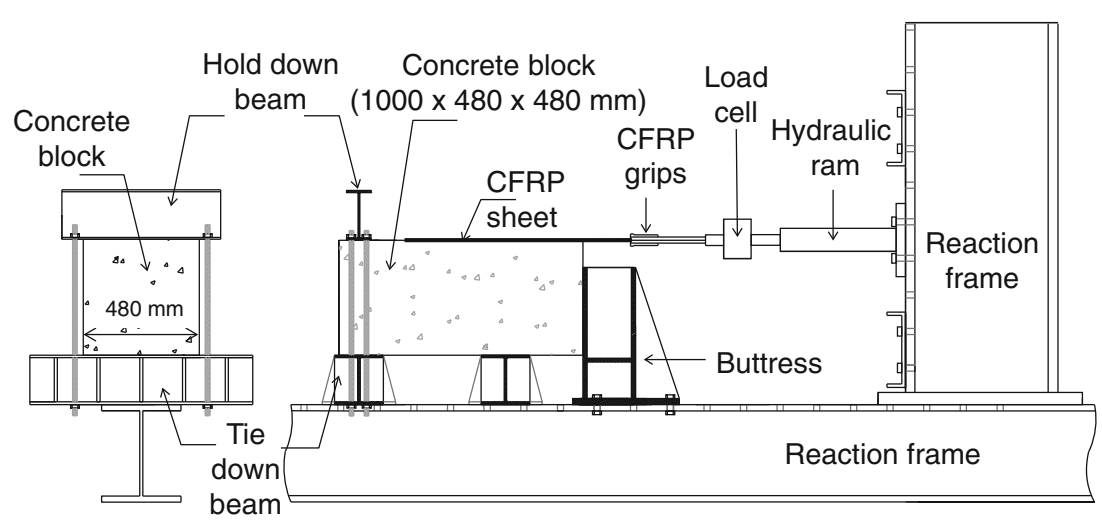

(a) Cross-sectional view

(b) Side view

Fig. 1 Typical single shear test setup. 
The length of the leading un-bonded region varied in each specimen but was equal to $127 \mathrm{~mm}$ in most of the specimens. An un-bonded distance equal to the sheet width of $127 \mathrm{~mm}$ was deemed sufficient.

The specimens tested by Niemitz et al. (2010) were divided into three groups (A, B, and $\mathrm{C}$ ) according to existence and arrangement of FRP anchors. Group A specimens were only bonded, group B had combinations of bonded regions and anchors of different sizes and patterns, and sheets in group $\mathrm{C}$ specimens were unbonded and attached solely using FRP anchors. Specimens tested by McGuirk and Breña (2012) were divided into two groups according to manufacturer of FRP material for comparison with the tests by Niemitz. Table 1 provides a summary of the main characteristics of the specimens in both research programs.

\subsection{Specimen Identification}

Specimens tested by Niemitz et al. were identified using an alphanumeric designation with four character groups separated by dashes. The first group of characters was used to identify the specimen group (A, B, or C) and the FRP anchor pattern used in the specimen (see Fig. 2). The second through fourth groups of numeric characters were used to identify characteristics of the FRP system (sheet and anchors). These characters designate the FRP sheet width, $w_{F R P}$, the FRP anchor diameter, $d_{a}$, and the FRP anchor splay diameter, $d_{s}$, respectively (all dimensions in centimeters). For example, specimen BII-13-1.3-5 represents a specimen in group B with an FRP anchor pattern II (Fig. 2), an FRP sheet width of $13 \mathrm{~cm}$, an FRP anchor diameter of $1.3 \mathrm{~cm}$, and an FRP anchor splay of $5 \mathrm{~cm}$.

The specimens tested by McGuirk and Breña were also identified using groups of characters according to the variables tested in this research program. The first letter in the specimen description indicates the FRP system ( $\mathrm{S}$ or F), and the number following this letter indicates the number of plies; the second set of characters indicates the number of FRP anchors ( $2 a$ or $4 a)$, the last number indicates the bonded length of the FRP sheet in inches; and a number before the bond length number, when present, indicates the longitudinal spacing between anchors as a function of splay diameter $\left(1 d_{s}\right.$ or $\left.2 d_{s}\right)$.

\subsection{Description of FRP Anchors}

The FRP anchors tested in these programs were fabricated manually using the same carbon-fiber material as was used for the FRP composite sheets. Each anchor consisted of a shaft region and a splay region. The anchor shaft had either a 1.3 or a $1.9 \mathrm{~mm}$ diameter. The anchor shaft was inserted into holes predrilled into the concrete, and the shaft region protruded from the concrete surface prior to wetting of the FRP sheet. All anchors had a $51 \mathrm{~mm}$ length to avoid interference with the reinforcement in the concrete blocks. This length is shorter than what is normally recommended for anchorage to concrete but did not seem to negatively affect the performance of the system as only a few anchor pullouts were observed. The hole in the concrete was partially filled prior to anchor insertion and filled to the top border after the anchor was inserted. The splay region was saturated at the same time as the FRP sheet was applied to the surface of the concrete.

To form the FRP anchors, the dry carbon-fiber sheet was cut perpendicularly to the fiber direction to the specific length required to form the anchor shaft and splay for a particular anchor. The length of carbon fiber sheet was obtained by adding the length of the anchor shaft and the radius of the desired anchor splay. Fibers were then rolled to obtain the design anchor diameter and tied at several places along shaft region of the anchor. Fibers in the splay region were left untied and transverse stitches that held the dry carbon-fiber bundles together in some systems were also cut. Pictures illustrating the different types of FRP anchors used are shown in Fig. 3.

\subsection{FRP Materials}

Three different FRP sheet manufacturers were studied in the tests. Niemitz et al. (2010) used sheets fabricated from a single manufacturer (FRP system M) and (McGuirk and Breña 2012) used sheets from two different manufacturers (FRP systems F and S). Unidirectional carbon fiber sheets bonded formed by wet layup were used in all cases. The published tensile strength, rupture strain, and elastic modulus of a 1-ply cured fiber-reinforced sheet from manufacturer M are $830 \mathrm{MPa}, 1.67 \%$, and $49.3 \mathrm{GPa}$, respectively. Similarly the published tensile strength, rupture strain, and modulus of a 1-ply cured sheet from manufacturers $\mathrm{S}$ are $849 \mathrm{MPa}$, $70.5 \mathrm{GPa}$, and $1.12 \%$; and those for manufacturer $\mathrm{F}$ are $875 \mathrm{MPa}, 72.4 \mathrm{GPa}$, and $1.2 \%$, respectively. These values are based on cured laminate thicknesses of $0.76 \mathrm{~mm}$ for manufacturer $\mathrm{M}$, and $1 \mathrm{~mm}$ for manufacturers $\mathrm{S}$ and $\mathrm{F}$.

\section{Observations on Behavior of Anchored FRP Systems}

General observations on the performance and critical parameters that affect the behavior of FRP systems with supplemental FRP anchors are presented here. Detailed discussions of the testing results that include additional comparisons among similar specimens and observations on measured strained are contained in the original references (Niemitz et al. 2010; McGuirk and Breña 2012).

\subsection{Observed Failure Modes in FRP Anchors}

Laboratory investigations performed by Niemitz et al. (2010) indicated three primary FRP anchor failure modes: FRP anchor splay delamination, FRP anchor shear rupture, and FRP anchor pullout. FRP anchor delamination is a failure mode that occurred between fibers forming the anchor splay and the FRP sheet surface. FRP anchor shear rupture consists of anchor failure just below the FRP sheet surface while the splay remained attached to the upper face of the FRP sheet. FRP anchor pullout was not a common failure mode and occurred only in cases where insertion holes in the concrete were perhaps improperly cleaned. 


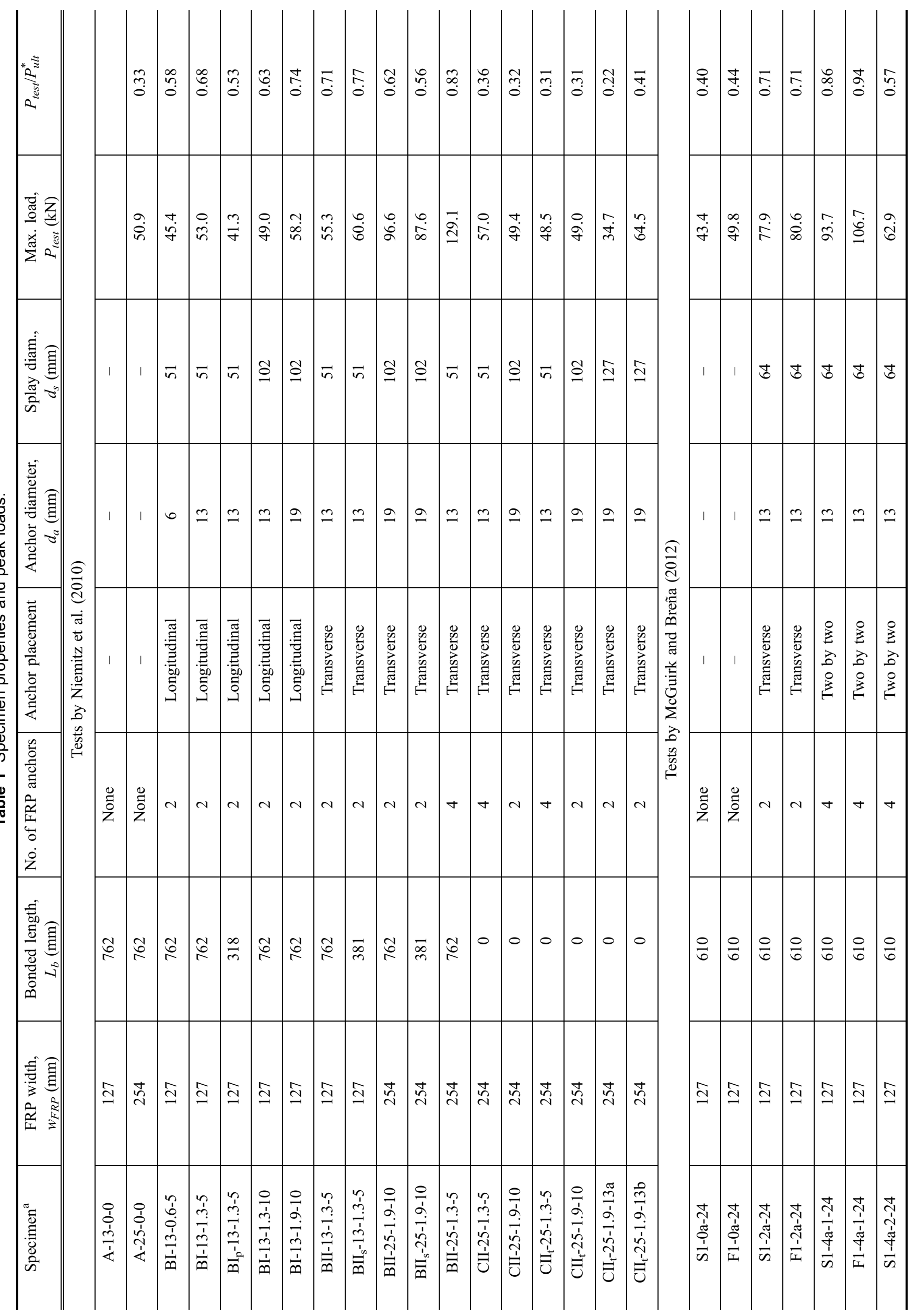




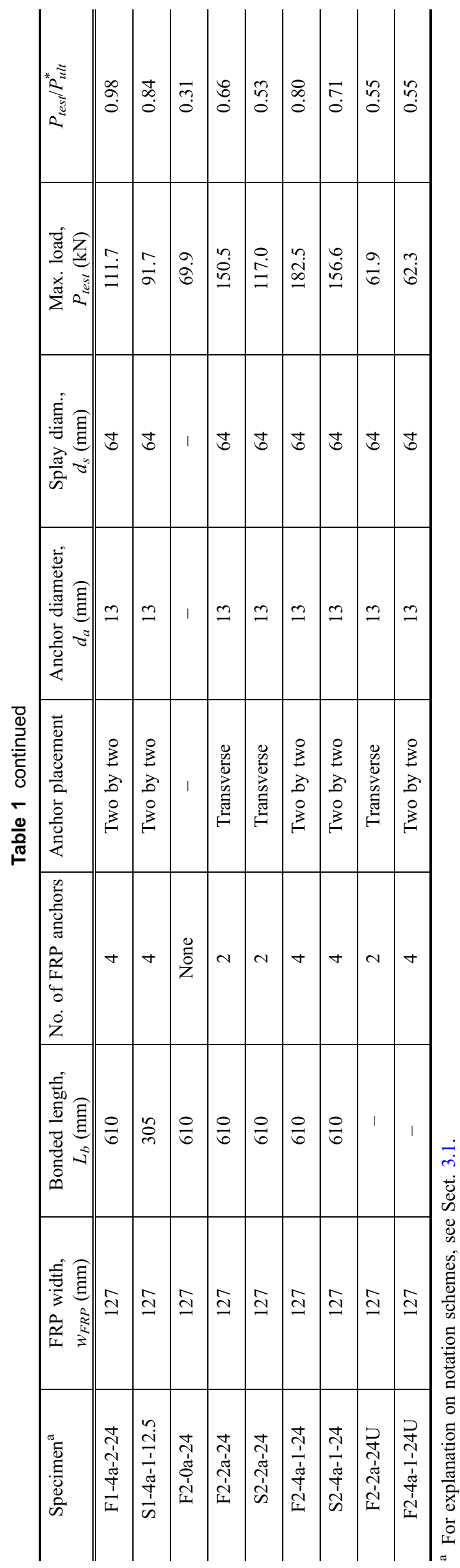

Anchor shear rupture resulted in cases where the shear capacity of the anchors was lower than the rupture strength of the FRP sheet. FRP anchor pullout was mostly associated to improper cleaning of the hole in which anchors were inserted. Anchor splay delamination was primarily triggered in stiff anchors that attracted significant force but that had smaller splay diameters than needed to develop the force the anchor was being demanded. Pictures illustrating these observed failure modes are shown in Fig. 4.

\subsection{Increase in Strength of Anchored FRP Sheets}

FRP anchors significantly improved the performance of the anchored and bonded FRP system over bonded-only sheets. A comparison in behavior between bonded sheets and bonded sheets with supplemental FRP anchors tested by Niemitz et al. (2010) and McGuirk and Breña (2012) revealed increases in peak load that varied depending on number of anchors and pattern. Single ply sheets with two anchors achieved increases between 155 and $182 \%$ relative to systems relying solely on bonding. Single ply sheets with four anchors were able to develop up to $224 \%$ higher load than the bonded companion specimens. Double ply systems with two and four anchors developed up to 273 and $366 \%$ increases, respectively, relative to the companion bonded specimens.

\subsection{Effect of FRP Anchor Splay Width}

For unidirectional FRP sheets, studies conducted by Niemitz et al. found that splay width plays an important role in development of FRP sheet force. Only regions of the FRP sheet within the width covered by the splay diameter were directly engaged. As a consequence longitudinal splitting occurred in specimens containing anchors that only partially covered the entire sheet width, so the peak force developed was a fraction of the rupture force for the entire FRP sheet. Regions of the sheet in front of the location of an anchor splay reached rupture but those outside failed by debonding after longitudinal splitting of the sheet (see Fig. 5). Therefore to fully develop the rupture strength of the FRP sheet, anchors splays should fully cover the width of unidirectional FRP sheets. This important finding was used to design the tests reported by McGuirk and Brena, where the entire width of sheet was engaged in all their tests.

\subsection{Effect of Anchor Longitudinal Spacing}

Longitudinal spacing of anchors or anchor groups may have two effects depending on the distance between centerlines of anchors. For anchors that have a large longitudinal spacing, the strains in the sheet behind the first row of anchors dropped significantly. The second row of anchors did not contribute to force development in the FRP sheet until the debonding front had passed beyond the first row of anchors. At this point, the force in the sheet was developed by the first row of anchors and a combination of anchor and bond in the region surrounding the second row of anchors. The effect of anchors spaced widely apart in the longitudinal direction was to increase the ductility of the system without affecting the strength of the system significantly.

8 International Journal of Concrete Structures and Materials (Vol.7, No.1, March 2013) 


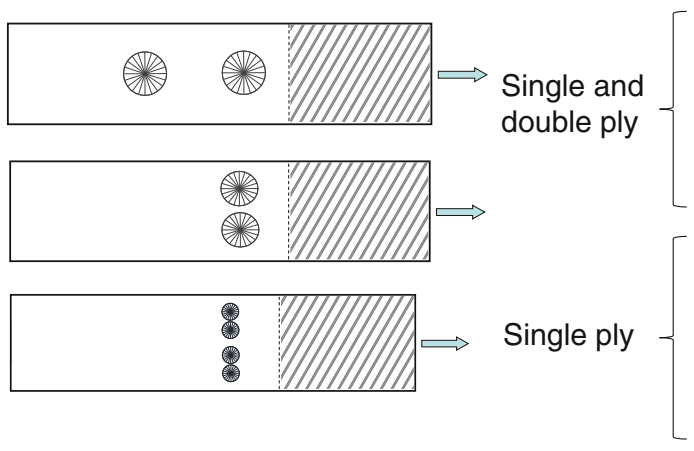

(a)

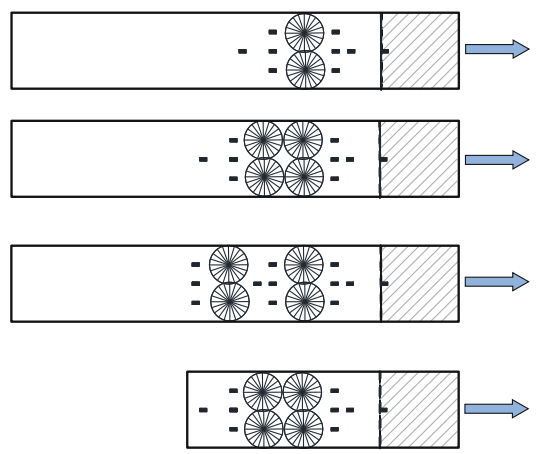

(b)

Fig. 2 Anchor patterns: a tested by Niemitz et al. (2010), b tested by McGuirk and Breña (2012) (hatching denotes region of un-bonded FRP sheet).

(a)
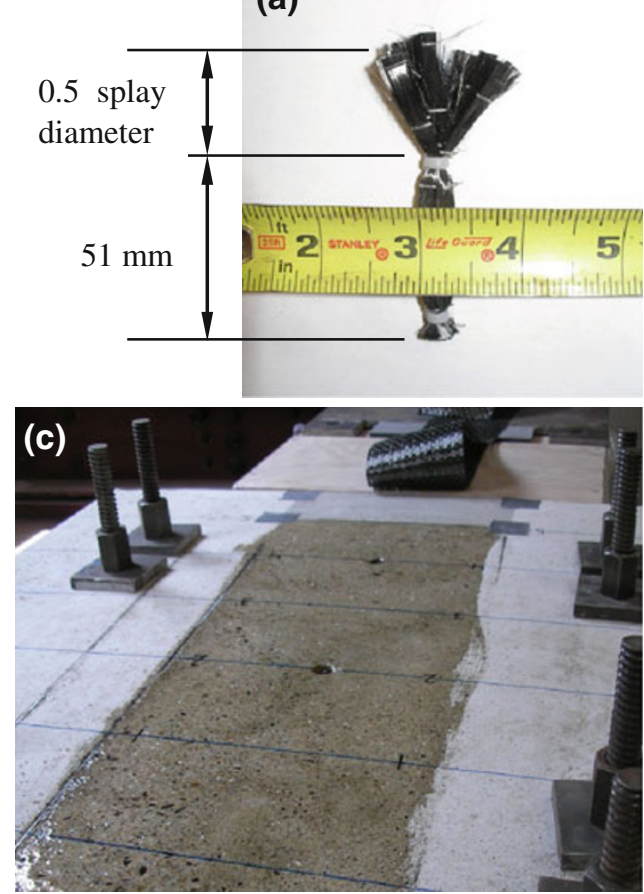
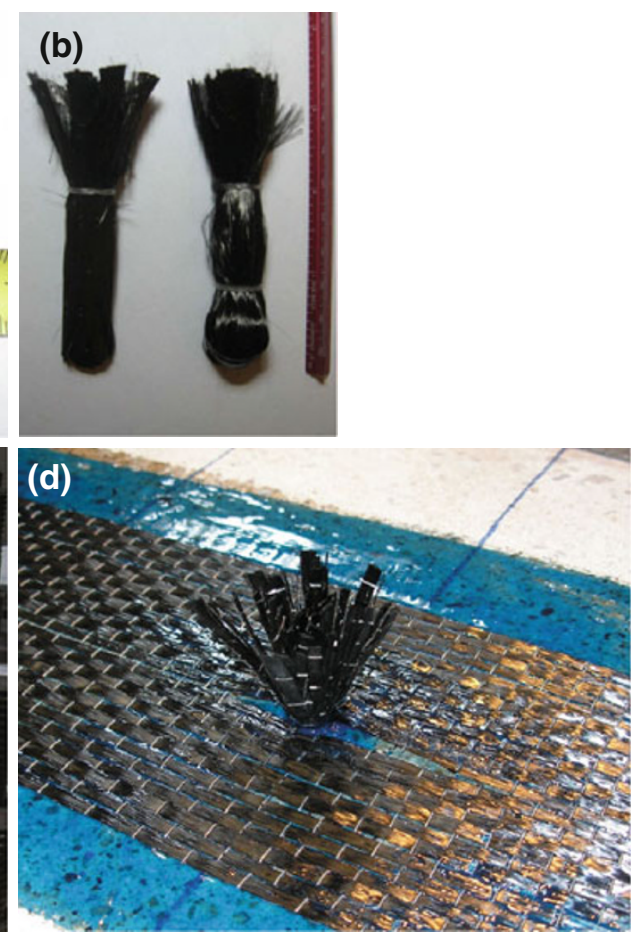

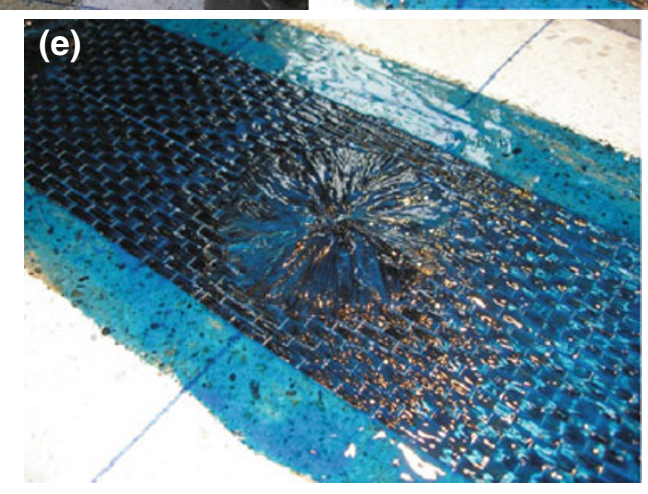

Fig. 3 Schematic of anchor fabrication and installation procedure: a anchor for system $\mathrm{M}, \mathbf{b}$ anchors for systems $\mathrm{S}$ and $\mathrm{F}$, $\mathbf{c}$ surface preparation, primer application, and

In contrast, anchors placed close together in the longitudinal direction behaved as a group and led to higher force being developed in the FRP system. Anchors placed within the stress transfer zone of the bonded sheet were effective in increasing the force in the sheet, since they allowed higher drilling; d FRP sheet application and anchor, and e finished FRP anchor and sheet installation.

stresses to develop through a combination of bond and anchorage. If multiple rows of anchors are needed to develop the strength of FRP sheets, these rows must lie within the stress transfer zone or will otherwise be relatively ineffective (Fig. 6). 

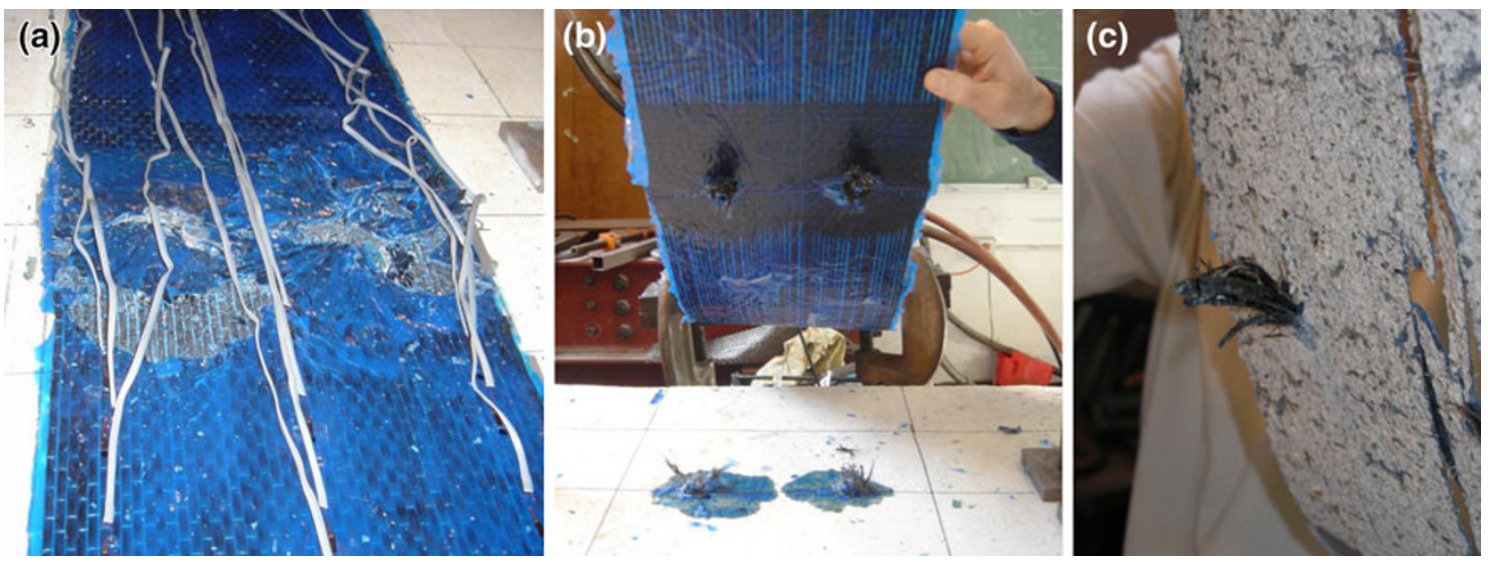

Fig. 4 Observed failure modes: a FRP anchor delamination, b FRP anchor shear rupture, c FRP anchor pullout.

\subsection{Effect of Number of FRP Sheet Plies}

Increasing the number of FRP plies had the effect of increasing the demand on FRP anchors because of an increase in strength and stiffness of the FRP laminates. Although the strains developed in the FRP sheet were of similar magnitude (see Fig. 7), the peak force generated in the FRP sheets with two plies was significantly larger due to the increase in thickness of the laminate. This result indicates that FRP anchors may effectively be used to anchor FRP sheets consisting of multiple plies.

\section{Finite Element Modeling}

Finite element modeling of the bonded and bondedanchored FRP sheets was conducted to determine the peak load for different anchor arrangements, the theoretical longitudinal and transverse strain distributions on the FRP sheets, and to compare these theoretical values to measured strains. Additionally, these models may also be used in future studies to identify FRP anchor parameters needing experimental verification to allow an accurate characterization of anchor behavior for future modeling. Only results of a few key specimens tested by Niemitz et al. (2010) are presented here because of space, but similar results were obtained from other specimens that were modeled.

The finite element models consisted of a two-dimensional plan representation of the FRP sheet and interface elements connecting the sheet to the concrete substrate. The FRP sheet was modeled using thin shell elements with orthotropic material properties. Linear-elastic material properties were assumed for the shell elements. Poisson's ratio was assumed equal to 0.30 for lack of a more accurate value for the type of laminates used. This type of modeling contrasts with most of the finite element models that have been used to date to characterize the bond performance of FRP sheets in the longitudinal direction, where the transverse dimension of the sheet is compressed into a line using plane stress approximation to the sheet-concrete interface.

The interfacial behavior was modeled using nonlinear spring elements connected to each shell node in the longitudinal and transverse directions on one end, and fixed at the

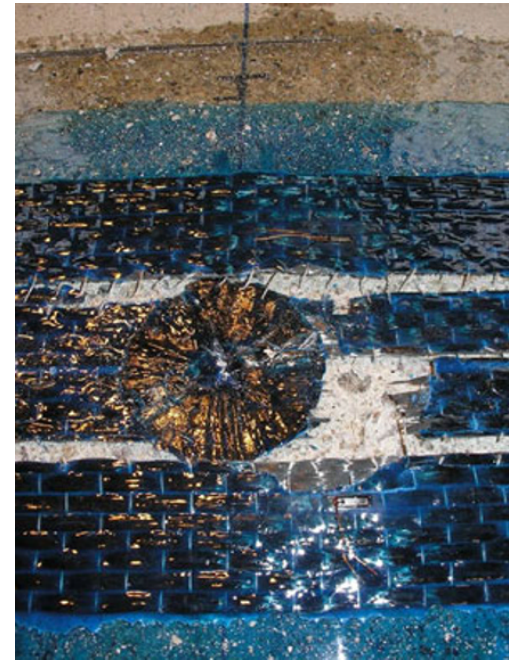

Fig. 5 Partial engagement of FRP sheet.

other end. Concrete was assumed rigid at depths beyond the interface-shear stress transfer zone, defined within the top $5 \mathrm{~mm}$ from the concrete surface consistent with the value proposed by Lu et al. (2005). This assumption obviated the need to model the concrete substrate explicitly using nonlinear solid elements, which would have been much more computationally expensive. The spring force-deformation properties were calculated using the bond stress-slip model proposed by $\mathrm{Lu}$ et al. (2005), where the force in each spring was determined by multiplying the shear stress from the model by the tributary area of each spring. The simplified model proposed by $\mathrm{Lu}$ et al. was converted into a multi-linear model to simplify the calculations (see Fig. 8b). This spring force-deformation relationship was then calibrated to better match the test results of specimens without anchors (A-13-0-0 and A-25-0-0). Parameters defining the interface springs are listed in Table 2. The properties of these bond springs were also used to model bonded regions in specimens that included FRP anchors.

The geometry of the finite element models used is illustrated in Fig. 8a. The typical characteristics of the spring force-deformation behavior used in this research are shown in Fig. 8b. Springs representing FRP anchor response were assigned different force-deformation properties than those 


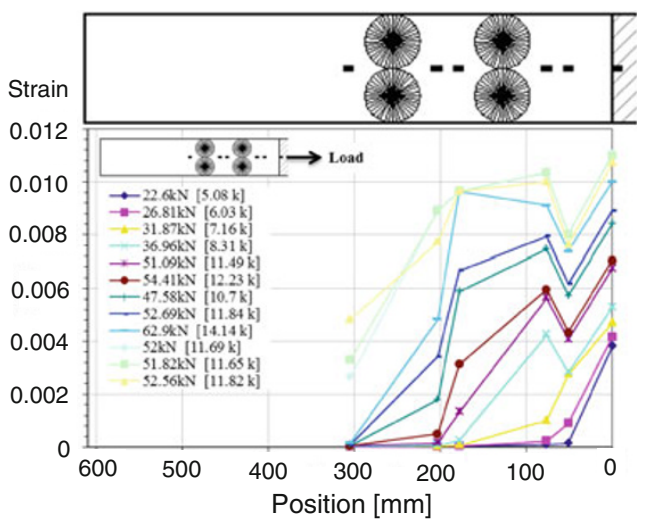

(a) Specimen S1-4a-2-24



(b) Specimen S1-4a-1-24

Fig. 6 Effect of longitudinal spacing of FRP anchors (McGuirk and Breña 2012).

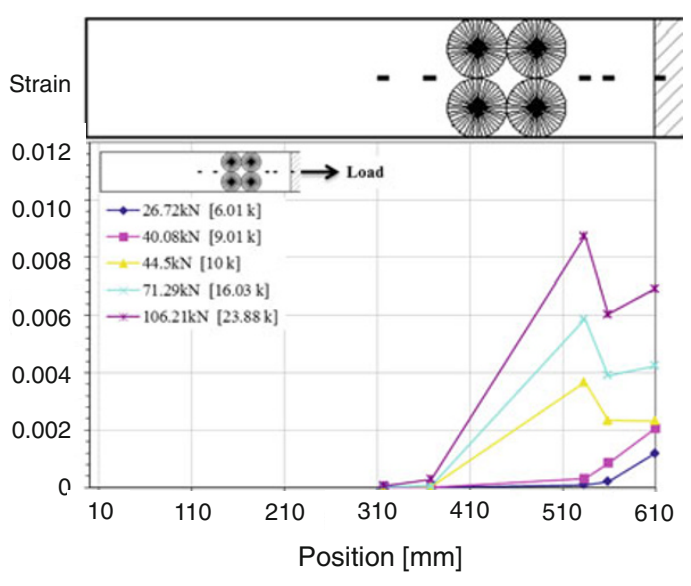

(a) Specimen F1-4a-1-24

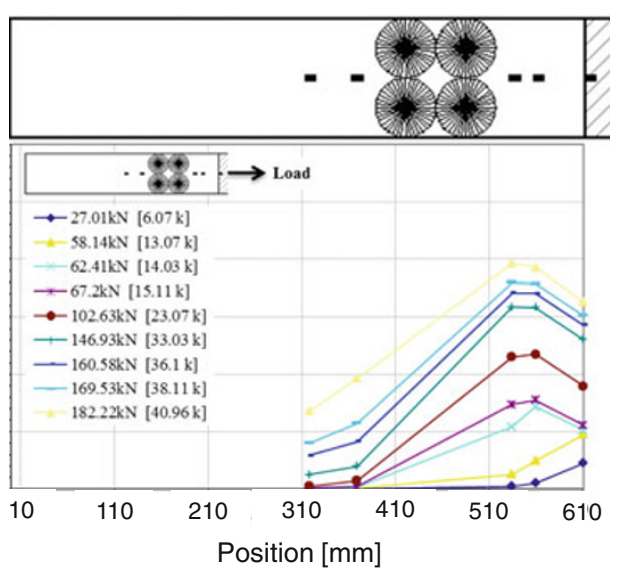

(b) Specimen F2-4a-1-24

Fig. 7 Effect of number of plies on longitudinal strains (McGuirk and Breña 2012).

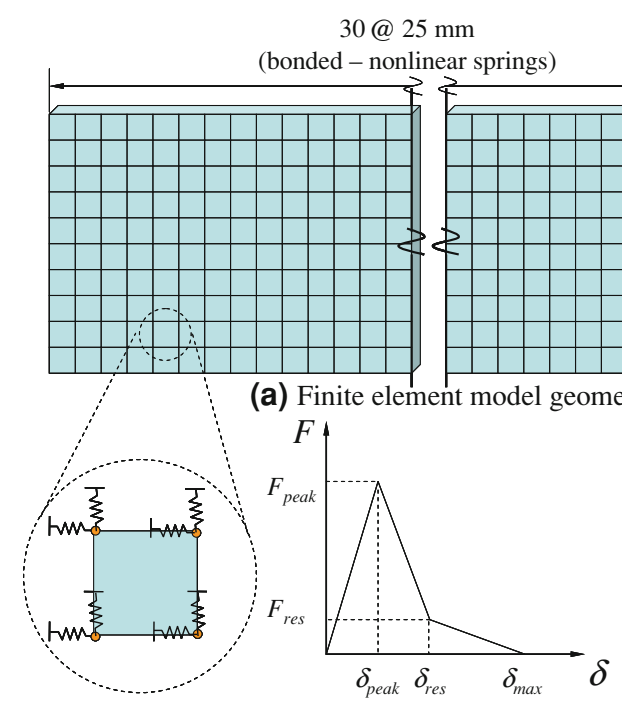

(b) Interface spring forcedeformation response
5 @ $25 \mathrm{~mm}$ (unbonded)
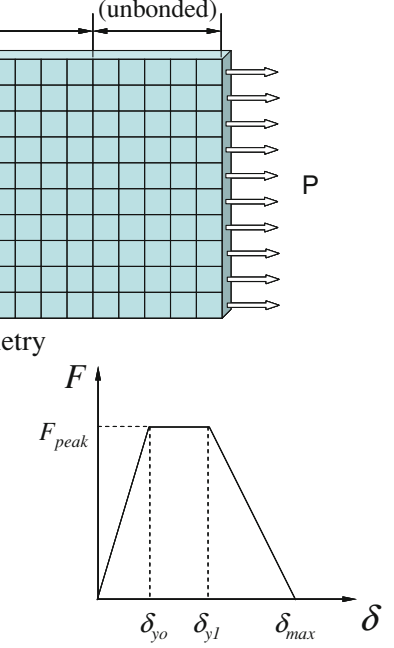

(c) FRP anchor spring forcedeformation response

Fig. 8 Finite element models: a geometry of finite element model and properties of nonlinear springs to model $\mathbf{b}$ the concrete-FRP sheet interface, and $\mathbf{c}$ the FRP anchors. 
used for the interface springs. The assumed force-deformation relationship for anchor springs is illustrated in Fig. 8c. The parameters defining the response of springs representing 13 or $19 \mathrm{~mm}$ diameter $\left(d_{a}\right)$ anchors, with a 51 or $102 \mathrm{~mm}$ splay diameter $\left(d_{s}\right)$, respectively, are listed in Table 2. As shown, different sets of force-deformation parameters were used to model the response of these FRP anchors of two different sizes, denoted as small and large in the table. These anchor types were used in Niemitz et al.'s specimens BI-13-1.3-5, BI-25-1.9-10, BII-25-1.3-5, BII-251.9-10, among others. The strength of these two anchor sizes was determined from testing of specimens in group $\mathrm{C}$ (Specimens CII-25-1.3-5 and CII-25-1.9-10), consisting of $254 \mathrm{~mm}$ wide sheets attached to the concrete blocks only

Table 2 Spring parameters for interface and FRP anchor modeling.

\begin{tabular}{c|c|c|c|c}
\hline & $\begin{array}{c}\text { Epoxy-concrete interface } \\
(127-\mathrm{mm} \text { wide FRP sheet })\end{array}$ & $\begin{array}{c}\text { Epoxy-concrete interface } \\
(254-\mathrm{mm} \text { wide FRP sheet })\end{array}$ & $\begin{array}{c}\text { Small FRP anchors } \\
d_{a}=13 \mathrm{~mm}, \\
d_{s}=51 \mathrm{~mm}\end{array}$ & $\begin{array}{c}\text { Large FRP anchors } \\
d_{a}=19 \mathrm{~mm}, \\
d_{s}=102 \mathrm{~mm}\end{array}$ \\
\hline \hline$F_{\text {peak }}(\mathrm{kN})$ & 0.53 & 1.1 & 17.8 & - \\
\hline$F_{\text {res }}(\mathrm{kN})$ & 0.05 & 0.11 & - & - \\
\hline$\delta_{\text {peak }}(\mathrm{mm})$ & 0.045 & 0.045 & - & - \\
\hline$\delta_{\text {res }}(\mathrm{mm})$ & 0.2 & 0.2 & 0.18 & 0.25 \\
\hline$\delta_{\text {yo }}(\mathrm{mm})$ & - & - & 0.51 & 0.64 \\
\hline$\delta_{\text {yl }}(\mathrm{mm})$ & - & - & 1.78 & 1.78 \\
\hline$\delta_{\max }(\mathrm{mm})$ & 1.78 & 1.78 & - & \\
\hline
\end{tabular}

$d_{a}$ diameter of anchor, $d_{s}$ diameter of splay.

Table 3 Comparison between measured and calculated peak load.

\begin{tabular}{c|c|c|c|c|c|c}
\hline Specimen & $P_{\text {test }}(\mathrm{kN})$ & $P_{F E M}(\mathrm{kN})$ & Difference (\%) & $\begin{array}{c}\text { Measured } C_{L} \\
\text { strain* }\end{array}$ & FEM $C_{L}$ strain* & Difference (\%) \\
\hline \hline A-13-0-0-0 & 35.6 & 34.5 & 3.1 & 0.0033 & 0.0062 & -87.9 \\
\hline BI-13-1.3-5 & 53.0 & 54.6 & -3.0 & 0.0100 & 0.0083 & 17.0 \\
\hline BI-13-1.9-10 & 58.2 & 60.0 & -3.1 & 0.0097 & 0.0097 & 0.0 \\
\hline A-25-0-0 & 50.9 & 49.8 & 2.2 & 0.0037 & 0.0047 & -27.0 \\
\hline BII-25-1.3-5 & 129.1 & 133.9 & -3.7 & 0.0084 & 0.0086 & -2.4 \\
\hline BII-25-1.9-10 & 96.6 & 99.0 & -2.5 & 0.0072 & 0.0080 & -11.1 \\
\hline
\end{tabular}

* Section at $730 \mathrm{~mm}$ from the end of the sheet.

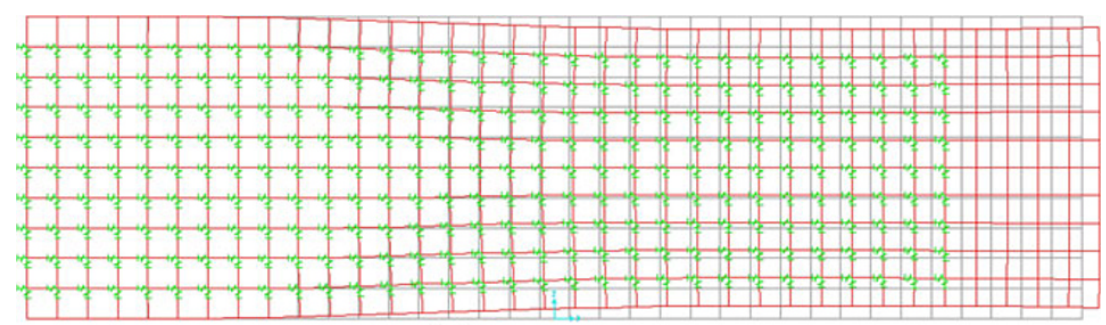

(a) Specimen A-25-0-0

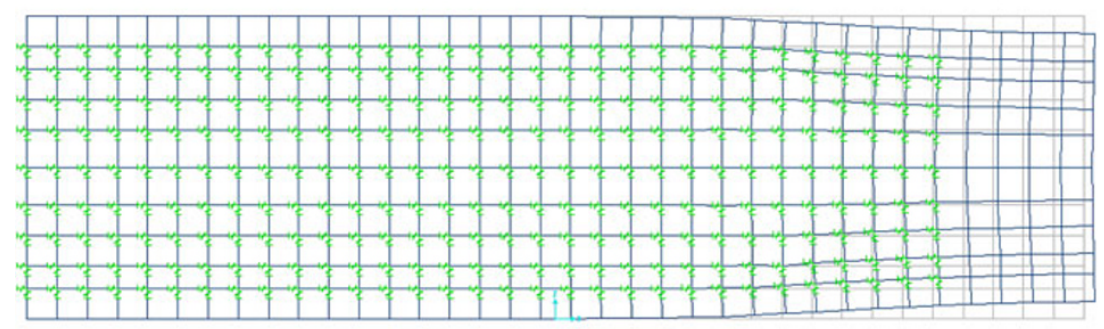

(b) Specimen BII-25-1.3-5

Fig. 9 Deformed shapes of models for specimens without and with anchors from tests by Niemitz et al. (2010).

12 | International Journal of Concrete Structures and Materials (Vol.7, No.1, March 2013) 
through FRP anchors. Unfortunately, detailed measurements to determine the deformation response of the anchors were not taken during the experiments so the values used were obtained by calibration based on agreement between the peak load determined in the finite element models and the peak force applied experimentally. Better definition of anchor properties and verification through experimental testing is required for future finite element modeling.

To test the validity of the interface spring models and the anchor spring models used in specimens with FRP sheet widths of 127 and $254 \mathrm{~mm}$, three selected specimens within each group were modeled. The three specimens selected within the $127 \mathrm{~mm}$ wide group were A-13-0-0, BI-13-1.3-5, and BI-13-1.9-10; the three specimens modeled in the $254 \mathrm{~mm}$ group were A-25-0-0, BII-25-1.3-5, and BII-251.3-10. The maximum calculated load and peak strain determined along the centerline of the sheet for all the models are presented and compared with experimentally determined values in Table 3 .

The agreement between the measured and calculated load in these six specimens is remarkably good given the simple nature of spring models selected to represent FRP anchor behavior. The maximum difference between measured and calculated force is less than $4 \%$. In contrast, a comparison between measured and calculated strains at a selected sheet section on the sheet centerline reveals higher differences (up to $27 \%$ difference) indicating the difficulty in capturing the deformation response without an accurate determination of detailed characteristics of the FRP anchor force-deformation response. The results, however, are promising and were used to provide an insight on the strain distribution and explain the observed debonding mechanism during the tests.

Only a detailed discussion of finite element results of specimens with a $254 \mathrm{~mm}$ sheet width is presented here although the findings were similar for the other group. The deformation response of models for specimens A-25-0-0 and BII-25-1.3-5 are illustrated in Fig. 9. Two important characteristics can be observed in these figures. First, it can be noted that as load is applied axially significant deformations occur in the transverse direction because of the orthotropic behavior assumed for the FRP sheets. Second, a comparison of the two graphs reveals that propagation of debonding toward the end of the sheet could be computed further in the model for specimen A-25-0-0. Convergence was not achieved in specimen BII-25-1.5-5 after the debonding front had just passed behind the location of FRP anchors, as can be seen by observing that only the leading edge (right) of the FRP sheet had debonded. The significant spring stiffness and strength differences between bonded regions of the sheet and FRP anchors are believed to be the major source of this behavior. Laboratory tests also revealed that the debonding front was able to propagate farther toward the unloaded end of the sheet for specimens without anchors.

Figure 10 illustrates three-dimensional plots of longitudinal and transverse strain distributions for models of specimens A-25-0-0, BII-25-1.3-5, BII-25-1.9-10 at loads equal to $44.5 \mathrm{kN}$. At this load level debonding propagation toward the unloaded end of the sheet had not initiated. These



(a) Specimen A-25-0-0

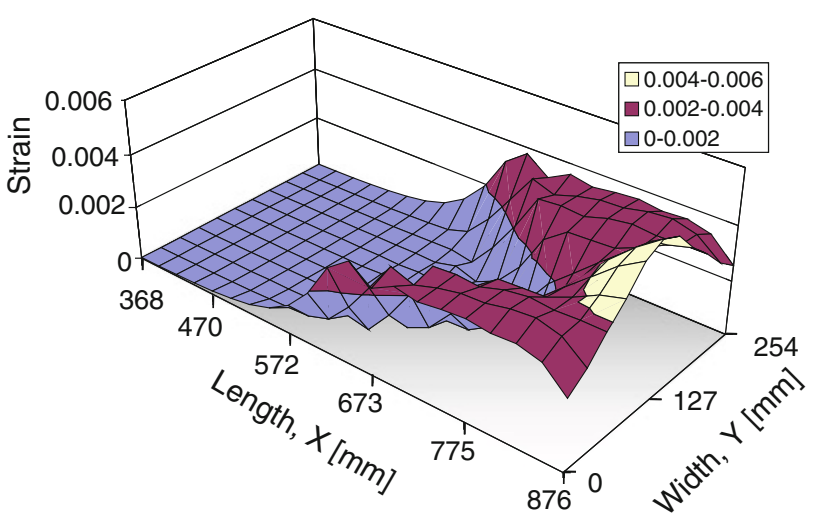

(b) Specimen BII-25-1.3-5

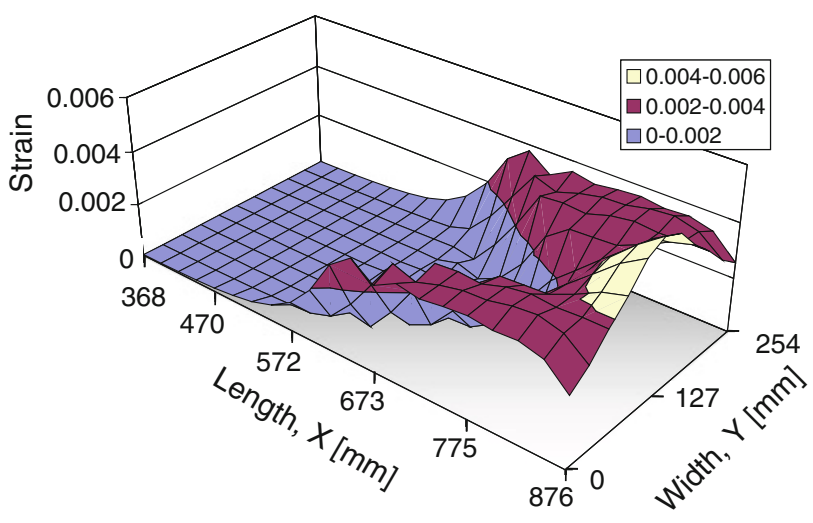

(c) Specimen BII-25-1.9-10

Fig. 10 Strain distribution at $\sim 44.5 \mathrm{kN}$.

specimens were selected to illustrate the general behavioral trends observed also in other specimens. They were also chosen to compare with the measured results presented earlier in this paper. The strain field is plotted for the portion within the loaded end of the sheet and a section located $368 \mathrm{~mm}$ from the end of the sheet. For reference, each shell element used to model the FRP sheet is $25 \mathrm{~mm}$ long. It can be noticed that the three plots are almost identical indicating that for this load level the influence of FRP anchors is negligible. The transverse distribution of strains exhibits an interesting variation. At the loaded end throughout a distance in the longitudinal direction of approximately $50 \mathrm{~mm}$, the highest calculated strains occur at the sheet centerline and decrease near the sheet edges. Beyond this section, the 


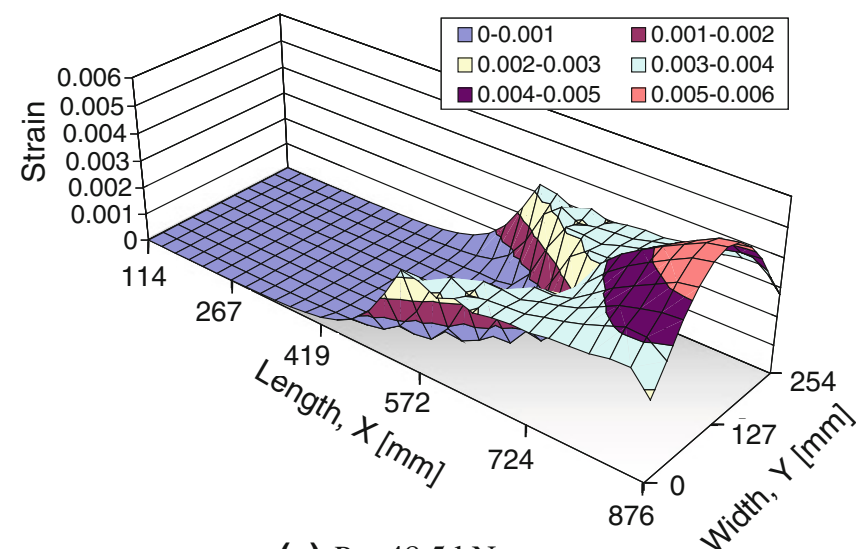

(a) $P=48.5 \mathrm{kN}$

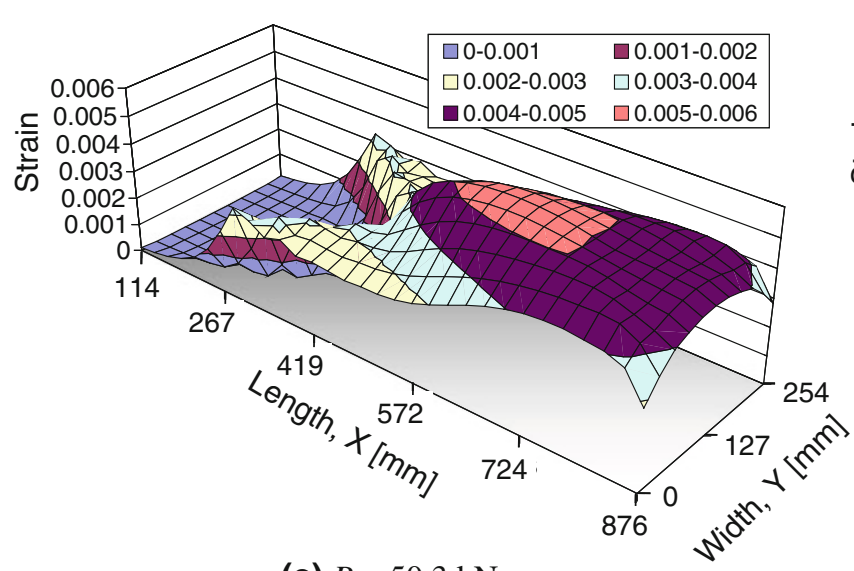

(c) $P=50.3 \mathrm{kN}$

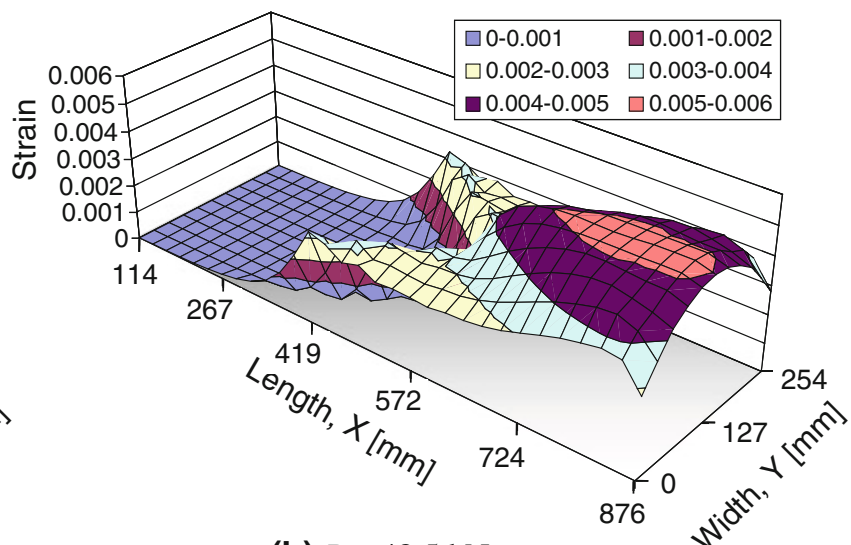

(b) $P=48.5 \mathrm{kN}$

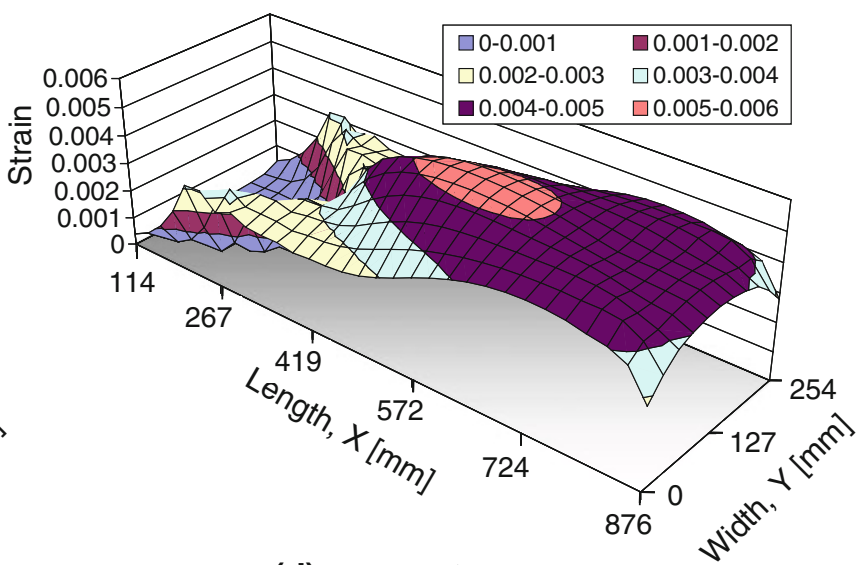

(d) $P=49.8 \mathrm{kN}$

Fig. 11 Calculated FRP strain distribution with progression of debonding in specimen A-25-0-0.

transverse strain distribution then exhibits peak strains near the edge with lower strains near the sheet centerline. The occurrence of higher strains along the edges explains why debonding typically initiated along the edge of the sheet in all specimens during the tests.

A slightly higher load initiated the propagation of debonding in these three specimens, and was similar for other specimens tested in this research. Debonding propagation in specimen A-25-0-0 is illustrated at four different steps of the finite element simulation in Fig. 11. The region of high strains in the center portion of the sheet extended back toward the end of the sheet at subsequent steps in the analysis at approximately the same applied load. The highest strain gradient observed along the sheet centerline in these plots corresponds to the so-called bond-stress transfer zone (Bizindavyi and Neale 1999; Subramanian et al. 2007), which extended approximately $127 \mathrm{~mm}$ in this specimen. Within the debonded region of the sheet (in front of the stress transfer zone), strains exhibit a longitudinal and transverse variation consistent with variations observed in the laboratory tests. The longitudinal strain variation observed in front of the stress transfer region is consistent with findings from Bizindavyi and Neale (1999) and Yao et al. (2005), among others.

Strain fields determined in specimens BII-25-1.3-5 and BII-25-1.9-10 at two different load levels are illustrated in Fig. 12. At a force of approximately $89 \mathrm{kN}$ debonding had reached the section where FRP anchors were located in these two specimens. Strain fields in the FRP sheet as shown in parts (a) and (c) of Fig. 12 exhibit a spike just in front of the approximate location where FRP anchors were situated, indicating that most of the force transfer occurred through the anchors. In contrast with specimen A-25-0-0, these strain concentrations keep increasing at applied loads approximating the failure load instead of dropping as the debonding front moved past the FRP anchor section. This result again highlights the fact that most of the force transfer occurred through the FRP anchors instead of the bonded region of the FRP sheet. Strain distributions in the transverse direction at the FRP anchor section have much higher variability than those observed in specimen A-25-0-0.

A comparison of calculated and measured strains at two different sheet sections is shown in Fig. 13 as debonding propagated toward the back of the sheet in specimen A-25-00 . These sections are located 381 and $483 \mathrm{~mm}$ from the unloaded end of the sheet. Measured strains follow the pattern obtained from the finite element model and show reasonable agreement with the measured values given the simple nature of the debonding model employed. Because of the high variability of transverse strains determined during the tests, a comparison between the measured and calculated transverse strain distribution was not conducted for specimens including FRP anchors. Further studies are needed to better establish the properties of the debonding model 


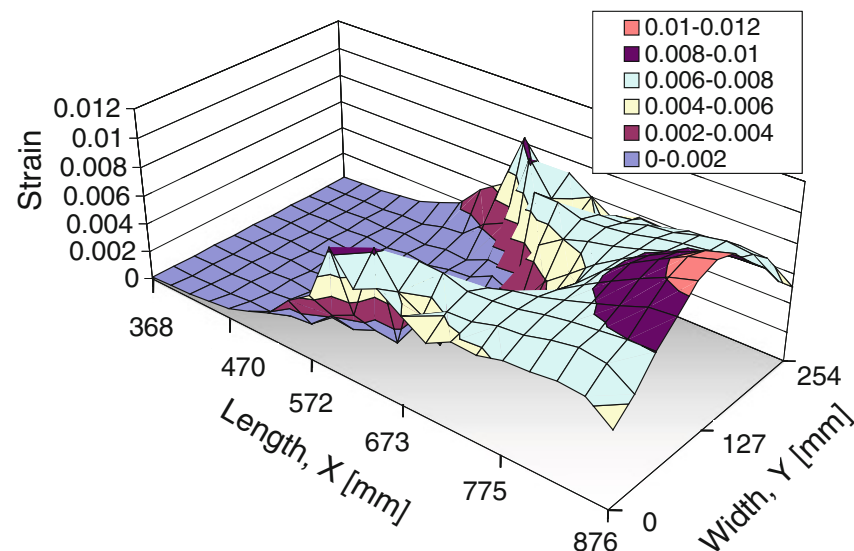

(a) $P=88.1 \mathrm{kN}$

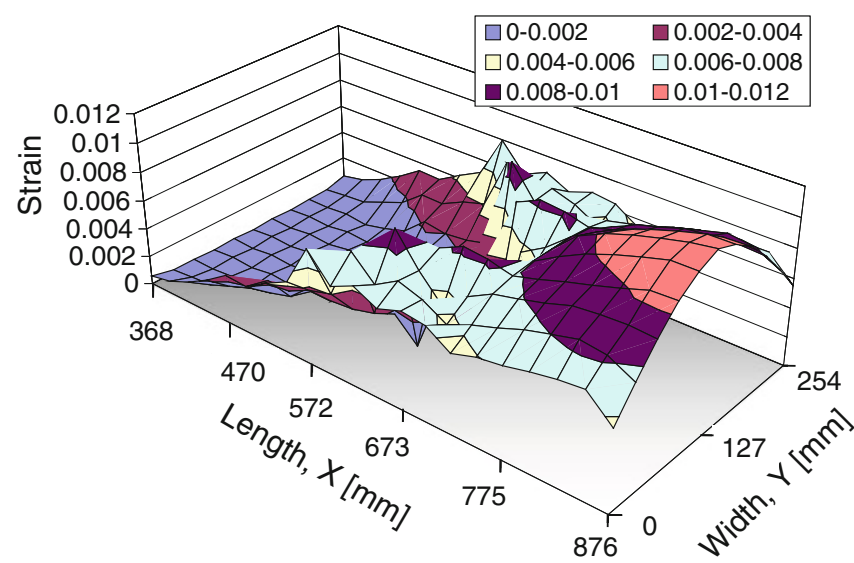

(c) $P=96.6 \mathrm{kN}$

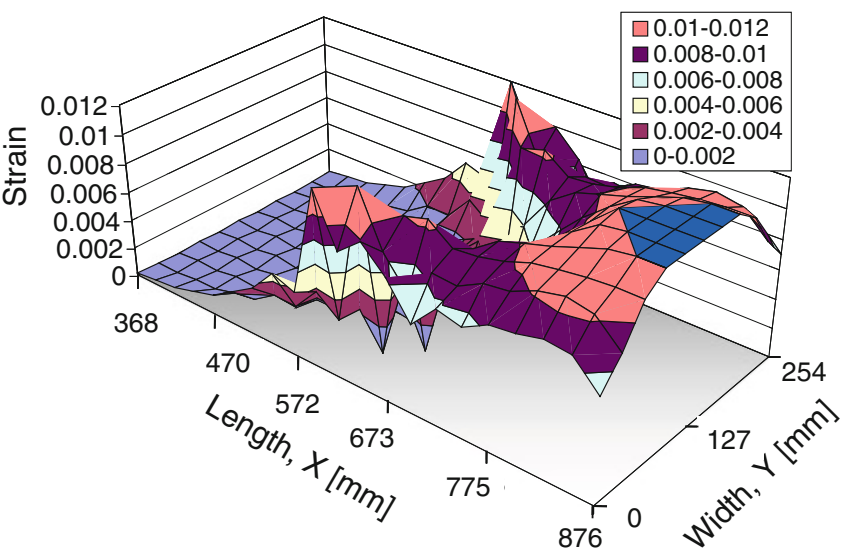

(b) $P=120.6 \mathrm{kN}$

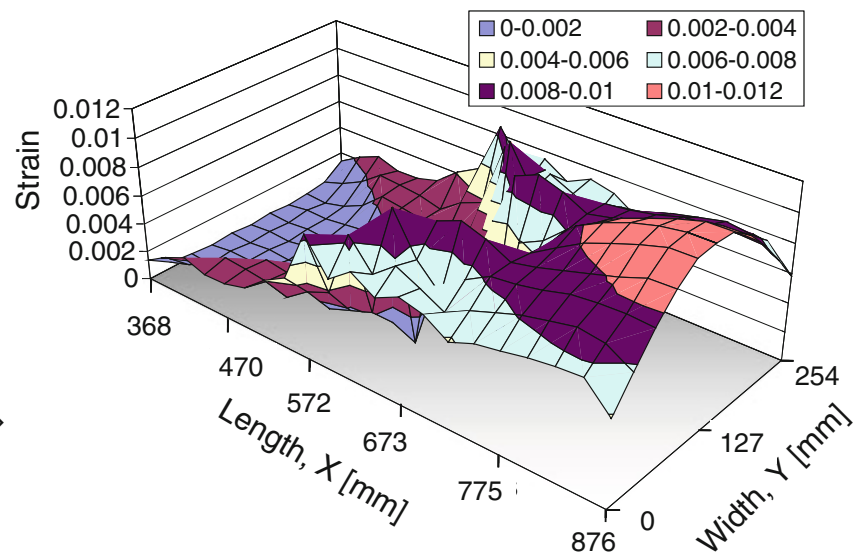

(d) $P=101.9 \mathrm{kN}$

Fig. 12 Calculated FRP strain distribution in specimens with two different FRP anchor arrangements: a, b Specimen BII-25-1.3-5, c, d specimen Bll-25-1.9-10.

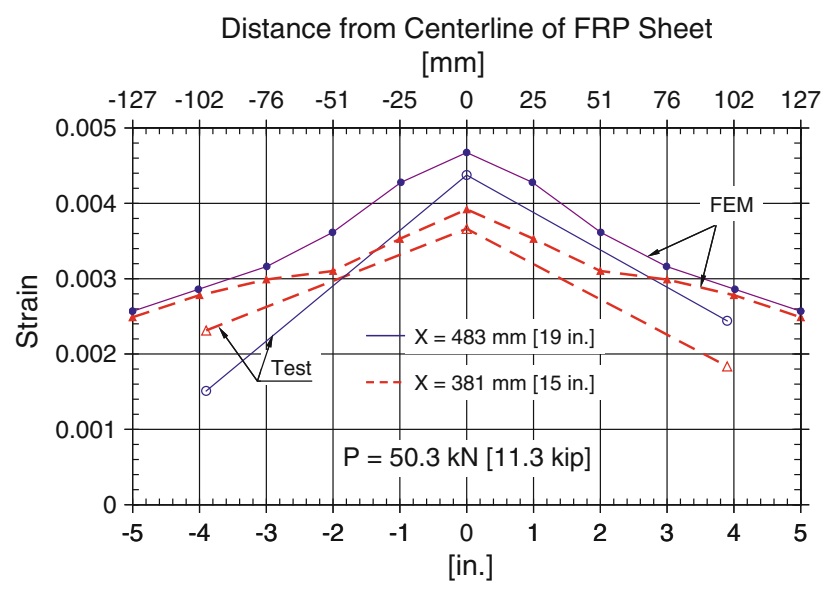

Fig. 13 Comparison of measured and calculated strains in specimen A-25-0-0.

(springs), particularly those characterizing anchor behavior, as strain results are particularly sensitive to the strength and stiffness parameters of the interface shear bond model.

\section{Conclusions}

FRP anchors can be used to increase the force and ductility of FRP sheets used in concrete strengthening applications. Anchorage of sheets has been tested in the past with different levels of success, but a comprehensive understanding of their behavior is still lacking and hinders the development of design recommendations. The studies reported in this paper represent an initial effort to improve the understanding of the complex interaction that takes place between FRP anchors and FRP sheets so that this anchoring system can be used more extensively. Based on the experimental and finite element simulations conducted to date, the following conclusions may be drawn:

1. Only sheet regions located within the anchor splay develop high stresses and strains. If sheet rupture is the design goal, then FRP anchors must fully cover the entire sheet width.

2. Longitudinal spacing of anchors should be limited to a distance located within the stress transfer zone of the FRP sheet. If the spacing exceeds this distance then anchors cease acting as a group and do not develop higher forces in the FRP sheet although they do increase the ductility of the system.

3. The anchor diameter should be sized according to the force demand in the sheet. More research is needed to determine appropriate models to determine anchor shear strength. 
4. Strain fields that develop in the FRP sheet are not uniform in the transverse direction. Strains plotted longitudinally along the FRP sheet centerline are not representative of distributions near the edge of sheets. Furthermore, in the case of sheets with FRP anchors, strains in the proximity of the FRP anchors can increase beyond those encountered at the sheet centerline. These observations have important implications for design of FRP anchored systems.

5. Finite element modeling of FRP anchored systems can be used to identify the parameters that affect behavior of sheets with complex anchor configurations. More robust and detailed models are needed to represent the characteristics of the force-deformation relationship of anchors to improve the fidelity of these models.

\section{Acknowledgments}

In kind material donations received for specimen fabrication from Barker Steel, BASF, Fyfe Co. and Sika are acknowledged with gratitude. The second author was supported by a graduate research fellowship from the Concrete Research Council of the American Concrete Institute to conduct some of the tests reported in this paper. ACI-CRC's support is appreciated.

\section{Open Access}

This article is distributed under the terms of the Creative Commons Attribution License which permits any use, distribution, and reproduction in any medium, provided the original author(s) and the source are credited.

\section{References}

Bizindavyi, \& Neale, (1999). Transfer lengths and bond strengths for composites bonded to concrete. Journal of Composites for Construction, 3(4), 153-160.

Breña, S. F., Bramblett, R. M., Wood, S. L., \& Kreger, M. E. (2003). Increasing the flexural capacity of RC beams using CFRP composites. ACI Structural Journal, 100(1), 36-46.

Chajes, M. J., Finch, W. W. Jr, Januszka, T. F., \& Thomson, T. A. Jr. (1996). Bond and force transfer of composite material plates bonded to concrete. ACI Structural Journal, 93(2), 295-303.

Coronado, C. A., \& Lopez, M. M. (2008). Experimental characterization of concrete-epoxy interfaces. Journal of Materials in Civil Engineering, 20(4), 303-312.

Elsayed, W. E., Ebead, U. A., \& Neale, K. W. (2009). Studies on mechanically fastened fiber-reinforced polymer strengthening systems. ACI Structural Journal, 106(1), $49-59$.
Eshwar, N., Nanni, A., \& Ibell, T. J. (2008). Performance of two anchor systems of externally bonded fiber-reinforced polymer laminates. ACI Materials Journal, 105(1), 72-80.

Khalifa, A., Alkhrdaji, T., Nanni, A., \& Lansburg, S. (1999). Anchorage of surface mounted FRP reinforcement. Concrete International, 21(10), 49-54.

Kim, S. J., \& Smith, S. T. (2009). Shear strength and behaviour of FRP spike anchors in cracked concrete. In Proceedings of FRPRCS-9, Sydney, Australia.

Kotynia, R., Baky, H. A., Neale, K. N., \& Ebead, U. A. (2008). Flexural strengthening of RC beams with externally bonded CFRP systems: Test results and 3D nonlinear FE analysis. Journal of Composites for Construction, 12(2), 190-201.

Lu, X. Z., Teng, J. G., Ye, L. P., \& Jiang, J. J. (2005). Bond-slip models for FRP sheets/plates bonded to concrete. Engineering Structures, 27, 920-937.

Mazzotti, C., Savoia, M., \& Ferracuti, B. (2009). A new singleshear set-up for stable debonding of FRP-concrete joints. Construction and Building Materials, 23(4), 1529-1537.

McGuirk, G. N., \& Breña, S. F. (2012). Development of anchorage system for FRP strengthening applications using integrated FRP composite anchors. Report No. CRC \#54, ACI Concrete Research Council, 277 pp.

Nakaba, K., Kanakubo, T., Furuta, T., \& Yoshizawa, H. (2001). Bond behavior between fiber-reinforced polymer laminates and concrete. ACI Structural Journal, 98(3), 359-367.

Niemitz, C. W., James, R., \& Breña, S. F. (2010). Experimental behavior of carbon fiber-reinforced polymer (CFRP) sheets attached to concrete surfaces using CFRP anchors. Journal of Composites for Construction, 14(2), 185-194.

Orton, S. L., Jirsa, J. O., \& Bayrak, O. (2008). Design considerations of carbon fiber anchors. Journal of Composites for Construction, 12(6), 608-616.

Ozbakkaloglu, T., \& Saatcioglu, M. (2009). Tensile behavior of FRP anchors in concrete. Journal of Composites for Construction, 13(2), 82-92.

Pellegrino, C., Tinazzi, D., \& Modena, C. (2008). Experimental study on bond behavior between concrete and FRP reinforcement. Journal of Composites for Construction, 12(2), 180-189.

Popovics, S. (1973). A numerical approach to the complete stress-strain curve of concrete. Cement and Concrete Research, 3(5), 583-599.

Smith, S. T., \& Teng, J. C. (2002a). FRP-strengthened RC beams-I: Review of debonding strength models. Engineering Structures, 24(4), 385-395.

Smith, S. T., \& Teng, J. C. (2002b). FRP-strengthened RC beams-II: Assesment of debonding strength models. Engineering Structures, 24(4), 397-417.

Subramaniam, K. V., Carloni, C., \& Nobile, L. (2007). Width effect in the interface fracture during shear debonding of FRP sheets from concrete. Engineering Fracture Mechanics, 74(4), 578-594.

Yao, J., Teng, J. G., \& Chen, J. F. (2005). Experimental study on FRP-to-concrete bonded joints. Composites: Part B, 36, 99-113. 